\title{
Applications, Model Study and Commercial Utilization (Patents) of Ophthalmic Route as Drug Delivery Site
}

\author{
Agrawal $\mathrm{H}^{*}$, Sharma PK and Malviya R \\ Department of Pharmacy, School of Medical and Allied Sciences, Galgotias University, India
}

\begin{abstract}
Ophthalmic drug delivery has been a noteworthy challenge for the researchers because of its one of a kind anatomy and physiology which consists of different sorts of boundaries, such as layers of cornea, sclera, and retina, etc. these obstructions can cause challenges for drug delivery and also in a dosage form, significantly into the posterior part of the eye. To defeat these sorts of issues different types of dosage forms have been developed such as nanoparticles, nano micelles, liposome, and micro-emulsions. Ongoing endeavors in research for ophthalmic drug delivery principally have concentrated on the frameworks which demonstrated that drugs are administered as in the form of eye drops. Because of the intense efforts of researchers, huge progressions in the following areas have been made, areas like in situ forming gels, oil in water emulsions, colloidal drug delivery systems, etc. The present article represents the overview of various factors which affects absorption and also clarifies about the use of media like bio-relevant media for eyes. This review will also explains about the transport of peptides and proteins through eyes, factors governing precipitation of drugs into eyes, vaccination through eyes as well as mechanistic study for drug absorption. Additionally, this article also summarizes different patents which are based on ophthalmic delivery of active agents. Delivery of drugs by ophthalmic route has been proved advantageous for future perspectives.
\end{abstract}

Keywords: Ophthalmic drug delivery; Implants; Protein delivery; Ophthalmic barrier; Model study; Biorelevant media

\section{INTRODUCTION}

Ocular administration of the drug is preliminary related with the need to treat diseases associated with eyes and is not regarded as a means for having systemic drug action. Systemic delivery of drugs via eyes as a portal is generally avoided to prevent the risk of eye damage from higher concentrations of drug which are not intended for the eye. Human eyes have unique anatomy, physiology as well as biochemistry which renders the ethereal impermeable for foreign substances thus introducing a constant summons to the developer to sidestep the protective barriers of the eyes without causing any permanent tissue damage. The eye is known to be a unique organ anatomically as well as physiologically that consists of various types of structures having specific functions. The eye has an exceptional quality which allows the delivery of local drugs as well as a noninvasive assessment of the disease. On the other hand, it is also a complex organ that makes drug delivery a challenging task for the researchers [1]. For the delivery of therapeutic agents to the target tissues, the barriers of the eye must be avoided efficiently without creating any difficulty to the patients. This challenge is currently being monitored by developing novel techniques for non-invasive delivery systems as well as improving the existing techniques [2]. The major routes for drug delivery into the eyes are a topical, systemic and intra-ocular injection. Basically topical route is preferred over other systemic administration for the treatment of eye diseases. This is due to the poor accessibility to systemic route and systemic administration of drug needs more time for achieving therapeutic concentration at the desired site of action. The formulations available for topical applications include suspensions, solutions, gels, ointments, etc [3]. Controlled delivery systems like a disposable lens, mini tablets, ocular inserts can be applied on the external surface of the eye for the treatment of the exterior segment of the eye. Liposomes and nanoparticles have been used to improve the bioavailability of the drug by extending the residence time and also tend to improve the penetration of the drug [4]. Generally, delivery of drug molecules through eyes can be achieved by using the following approaches:

\section{Contact lens and collagen shields}

The utilization of the contact lens which is hydrophilic for the administration of drugs was assessed firstly over three decades

Correspondence to: Harshita Agrawal, Department of Pharmacy, School of Medical and Allied Sciences, Galgotias University, Uttar Pradesh, India, Tel: +91-9454942427; E-mail: harshita28497@gmail.com

Received: February 14, 2019; Accepted: February 21, 2019; Published: February 28, 2019

Citation: Agrawal H, Sharma PK, Malviya R (2019) Applications, Model Study and Commercial Utilization (Patents) of Ophthalmic Route as Drug Delivery Site. Pharm Anal Acta 10:607. doi: 10.35248/2153-2435.19.10.607

Copyright: (C) 2019 Agrawal H, et al. This is an open-access article distributed under the terms of the Creative Commons Attribution License, which permits unrestricted use, distribution, and reproduction in any medium, provided the original author and source are credited. 
back. In spite of the fact that a longer duration of effect was seen with different classes of drugs, whereas no product of this class has been endorsed or popularized yet. Although, recent activities of patent demonstrate continuous research in particular areas. In a preclinical investigation, improved intraocular delivery of gentamycin was seen using this system in Rabbits. In another study, this is observed that there was no significant difference in antibiotic efficacy of Gatifloxacin either delivered via collagen shields or via standard eye drops [5].

\section{Iontophoresis}

The utilization of an electric current to improve the drug delivery via sclera is a different perspective which has been known for decades and recently it has been assessed by GAP and also to deliver drugs of different variety in which some are still under clinical development [6].

\section{Improved eye drops}

Research endeavors have assessed the advantages of increasing the uniformity of eye drops to enhance the contact time and along with this, increasing the minimum effective concentration duration. It has been seen in the case of pilocarpine that the duration of action does not enhance sufficiently. In other cases like timolol, its gel forming system persuades gellan gum was somehow more efficacious than maleate solution.

\section{Erodible implants}

Researchers have formulated an erodible implant which is having an advantage that it does not require any surgical procedure after the content that is the drug is exhausted. In a literature survey, it has been studied that dexamethasone is developed as an implant into the anterior chamber of the eye. This formulation reveals the result similar to the eye drops that are used in post-surgical inflammation treatment. In the case of macular edema which persists for a longer time has been treated by the formulation of dexamethasone and it shows good results than that of the untreated.

\section{Non-erodible implants}

Extensive literature survey reveals that a non-erodible intravitreal implant has been developed for the treatment of megalovirus retinitis. This perspective showed that a ganciclovir tablet is coated by ethylene vinyl acetate polymers and PVA and hence intravitreally implanted. This manufactured product was observed much more effective than that of intravenously injected ganciclovir. This product was found to be less toxic related to the delivery of ganciclovir intravenously. Comparatively, an innovation was utilized to form another drug delivery that is an implant which comprises of fluocinolone tablet enclosed in a silicone cup with a PVA membrane and a discharge cleft [7].

\section{Factors affecting absorption}

It is typically examined that medicine that is given into the cul-desac are quickly and completely consumed. Retention of medicines fundamentally happens through corneal or non-corneal route. The non-cornea pathway includes drug's absorption through the conjunctiva and the sclera in intraocular tissues yet this route isn't as beneficial as it limits the passage of drugs into the aqueous

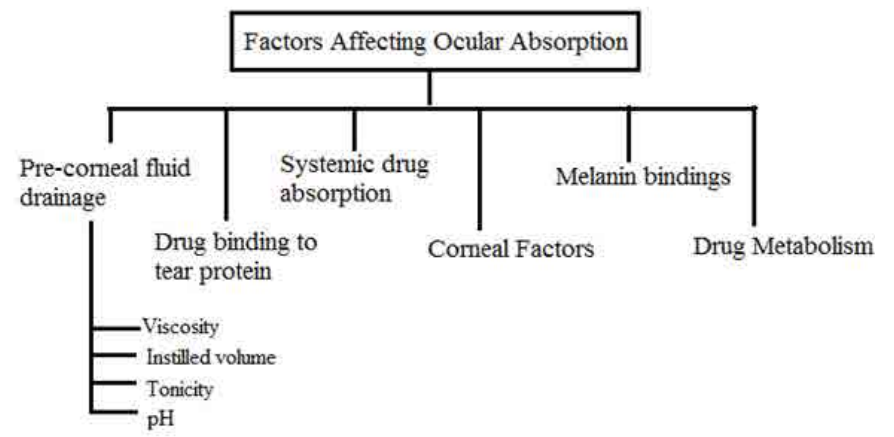

Figure 1: Factors affecting ocular absorption.

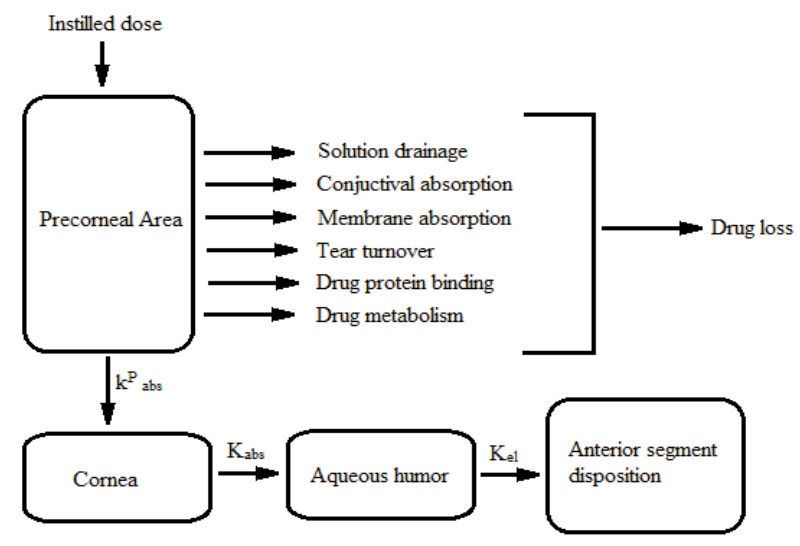

Figure 2: Mechanistic drug absorption.

humor. In this way, the corneal pathways are considered more beneficial as the drug's absorption across the corneal route has extreme absorption that prompts the drug into the aqueous humor. There are various factors which affect absorption of drugs into the eyes are enlisted into Figure 1 and details are as follows:

\section{Pre-corneal fluid drainage}

The principle behind low ocular drug absorption is precorneal fluid drainage. Instilling a noteworthy amount of drug is evacuated into the duct that is nasolacrimal duct. This duct helps in keeping the volume of the fluid up to $7-10 \mu \mathrm{l}$ all the time. A characteristic physiological system causes dropping of excess fluid which is drained out via nasolacrimal duct. These are some of the factors which influence drainage rate:

Viscosity: On increasing the viscosity of the instilled volume of drug the residence time of the solution in the conjunctival sac is increases.

Instilled volume: The more is the instilled volume of drug higher will be the drainage rate from the conjunctival sac.

Tonicity and drug type: Sometimes, the instilled volume of drug changes the physiological process of the ocular cavity. For example-A hormonal drug epinephrine helps in tear production, while some of the drugs like tetracaine diminish the production of tears. It has been studied that all the formulation for the ocular cavity must be isotonic with the tear fluid [8-10].

$\mathrm{pH}$ : The $\mathrm{pH}$ of the tear fluid must be 7.4 physiologically. All the ophthalmic preparations must be adjusted to the $\mathrm{pH}$ range of 7-7.7. 


\section{Drug binding to tear proteins}

$0.7 \%$ of the total body protein is contained by the tear fluid. The binding of the drugs to the tear protein leads to minimize the amount of free drug that is responsible for pharmacological action [11].

\section{Systemic drug absorption}

The systemic absorption of drugs may occur directly through the conjunctival sac or from the nasal cavity. Maximum of the systemic absorption occurs through a nasolacrimal duct which is administered topically and gives systemic side effects [12].

\section{Corneal factors}

The cornea consists of several layers of the cells. The outer layer is corneal epithelium and is lipid in nature whereas the hydrophilic layer is stroma consists of a maximum of the corneal thickness. The inner layer is the endothelium that separates aqueous humor and stroma [13].

\section{Melanin bindings}

The bioavailability of the drug administered topically can be changed by the pigments present into the ciliary body as well as iris that are melanin pigment. Some of the drugs having the good binding capacity with the melanin pigment release the drugs at a very slower rate [14].

\section{Drug metabolism}

Enzymes like cyclooxygenase, monoamine oxidase, cytochrome P450, etc manifests into tissues of the ocular cavity which metabolizes the API and ultimately leads to minimize the bioavailability of drugs in the ocular cavity [15].

\section{Simulation of dissolution in tear fluid}

Franz diffusion cell apparatus is apparently used to perform the dissolution studies and phosphate buffer can be used as a dissolution medium. The $\mathrm{pH}$ of the phosphate buffer should be maintained at 7.4 which will stimulate the tear fluid. [16,17].

\section{Use of bio relevant media for eyes}

As discussed, the ocular route is suitable only for treating the local condition problems of the eyes and not for the systemic drug absorption. The tears have a mean $\mathrm{pH}$ of 7.4 whereas sometimes there are variations. Tear fluid has the surface tension of 44.6$46.6 \mathrm{mNm}^{-1}$ for the normal healthy eyes and for the patient's eye it is $49.6 \mathrm{mNm}^{-1}$. In a study it is revealed that tear's osmolarity influences the tonicity of the tear fluid. The osmolarity of the normal saline solution is generally equivalent to the osmolarity of tear fluid. The osmolarity of the tear fluid found to be 290-310 $\mathrm{kg}^{1}$. Absorption of drugs into the eyes requires good pre-corneal penetration and prolonged contact time with corneal tissues. Ideally, the formulation should sustain drug release and maintain contact with the eye for extended periods of time. The extent of absorption into the eyes is severely limited by the physiological constraints such as reflex tearing and blinking. Further drug loss occurs from tear turn over, solution drainage by gravity and binding of drugs to proteins and other components of tears. As a result, typically only $1-2 \%$ of the instilled drug is bioavailable. The volume of tears in the eyes is about 5-10 $\mu$. The normal secretion is about $1-2 \mu \mathrm{l} / \mathrm{min}[18,19]$. The composition for simulated tear fluid includes sodium chloride, sodium bicarbonate, calcium chloride, purified water [20-22]. To evaluate in-vitro drug release of oligonucleotides macromolecules from the cationic nanoemulsion simulated tear fluid 1 was used in the quantity of $8 \mathrm{ml}$. potentially this is used for age-related treatment [23]. For the evaluation of the in-vitro drug release of pilocarpine, simulated tear fluid 2 was used in the quantity of $4 \mathrm{ml}$. Simulated tear fluid 2 was also used for the evaluation of in-vitro drug release of pilocarpine from nano-particles [24].

\section{Transport of protein and peptide through eyes}

Recent studies demonstrate that expanding the uses of proteins and peptides delivery through eyes can tackle inadequate controlled diseases and to improve the quality of patient's life $[25,26]$. Generally, the ocular route for the delivery of large molecules is not preferable, for example, Immunoglobulin $G$ which is an antibody can be administered through trans-sclera pathway via retina having negligible systemic absorption. There are certain challenges in the delivery of protein and peptide that are a loss of drug from ocular surface, blood-ocular barrier, lacrimal fluid barrier, consequent dilution, tear production and turnover, low contact time with the drug. There are currently some new approaches found which can overcome these challenges. The approaches include iontophoresis, micro-needles, prodrugs, etc [27].

\section{Vaccination through eyes}

The outermost portion of the ocular cavity has mucosa which is an entry gate for the foreign antigens. After the experiments, it is found that the vaccinations formulated into eye drops are efficacious against infections in mice. Vaccinations for influenza virus namely H1N1 influence mucosal antibody and systemic antibody responses that can prevent mice from the respiratory infection caused by influenza virus. Additionally, a vaccine against Salmonella is formulated and found effective against oral summons of salmonella which is in the form of eye drops and persuades LPS specific antibody. Unlike with the intranasal route, eye drop vaccinations did not redirect administered $\mathrm{Ag}$ into the CNS in the presence of CT [28]. When mice vaccinated by the eye drop, even after occlusion of the tear drainage from eye to nose, Ag-specific systemic IgG and mucosal IgA antibodies could be induced effectively of eye drops with OVA plus CT induced organogenesis of conjunctiva-associated lymphoid tissue and increased microfold cell-like cells on the conjunctiva-associated lymphoid tissue in the nictating membrane on conjunctiva, the mucosal side of the external eye. On the basis of these findings, we propose that the eye drop route is an alternative to mucosal routes for administering vaccines [29].

\section{Precipitation of drug into eyes}

Ocular side effects are majorly caused by drugs, in which some particularly belong to a class of drug or any specific route of administration like hyperpigmentation and trichomegaly is caused in the patients who take prostaglandins topically, opacity is observed in the patients taking drugs like phenothiazines. Various fundamental drugs instigate corneal epithelial changes portrayed by accumulation that is available as vortex keratotherapy or crystalline precipitation. This accumulation is related to the medication 
instigated phospholipids such as precipitation of drugs or harm to the epithelium. The difference in the analysis could be confounded to the likeness of the conditions to accumulation because of of the hereditary or the systemic changes [30].

\section{Mechanistic study for drug absorption}

The medication which is administered into the cul-de-sac must enter the eye Drugs which are given by instillation must enter the eye and essentially do so through the non-corneal routes. These routes consist of drug diffusion through the conjunctiva and sclera and seem to be important for the drugs that are absorbed poorly across the cornea (Figure 2).

\section{Model study for ocular drug absorption}

To investigate the effect of nutrients on the ophthalmic disease, the development of the in-vitro cell culture model came into existence. It provides information regarding the detection of biomarkers on the cell surface for targeted drug delivery. In the endocytosis and transcytosis transport, the blood-retinal barrier (BRB) transport machinery play an important role which helps in the use of systemically administered medicine for ophthalmic diseases. Recent information on inner BRB transport is limited as compared to BBB. Due to the monotonous task of isolating of different ocular tissues since immortalized cell lines have an advantage over the primary cell line. Fixing up the immortalized cell is simple and its properties are adjudged to stay stable at different passages. On comparing with the primary cell the immortalized cells depict unusual properties in biological systems [31].

The conventional method to study transcorneal drug absorption from the isolated animal cornea is replaced by the development of cell culture models. The objective was to do comparison and determination of permeability and also the tightness of epithelium through cell culture model to reduce errors occurs during interlaboratory practice. Some of the new models such as CEPI, SIRC, HCE-T for epithelial cells; HCC, HCC-HCE-T for organotypic human cornea constructs; RHC and Epiocular are commercially available models through which data is compared which is obtained by bovine cornea excision. The transepithelial electrical resistance (TEER) method was used to analyze the barrier properties of the cornea. The TEER was also used to determine the permeability of absorbed materials along with its physical as well as chemical characteristics. This TEER investigation disclosed that the epithelial models are weak in barrier functions excluding HCE-T cell lines [32,33].

The motive of the study was to develop a model for which can depict organotypic corneal equivalent model for testing the barrier function. This model will be able to study the barrier function of epithelial, stromal as well as endothelial cells. This model uses three different drugs for the study. They are Pilocarpine $\mathrm{HCl}$, Befunolol $\mathrm{HCl}$, and Hydrocortisone $\mathrm{HCl}$. Stromal cell and immortalized HEC (Human Endothelial Cell) were used to develop a multilayered tissue in trans good cell culture in step by step manner. The light microscope was used for the analysis of the morphology with the use of different stains [34,35].

\section{Development of equation to predict ophthalmic drug Absorption}

Grass and his co-workers have given the corneal drug penetration mechanism from the viewpoint of kinetic modeling. This developed model relates the permeability coefficient to the partition coefficient as well as with the molecular weight [36,37]. From this model, the cornea is represented as a laminated membrane. The cornea is laminated by a lipid layer i.e., epithelium and an aqueous layer i.e., stroma [38]. The permeability coefficient of this laminated membrane is expressed as eqn. (1):

$$
\text { Kper }=\frac{1}{\frac{L s}{D s}}+\operatorname{Le}(D p+P D e)
$$

Where;

Kper=permeability coefficient,

$P=$ partition coefficient

Ls and Le=thickness of stroma and epithelium

$D s=$ apparent diffusion coefficient for stroma

$D e=$ apparent diffusion coefficient for epithelium,

$D p=$ apparent diffusion coefficient for epithelial pores.

Pores present on the epithelial layer are of very small size and hence diffusion through pores can be neglected. Therefore when $D p=0$ Eq. 2 can be rearranged to give eqn. (2):

$$
\text { Kper }=\frac{P}{P\left(\frac{L s}{D s}\right)}+\frac{L e}{D e}
$$

From equation 2 one can conclude that the epithelium is the barrier for small values of the partition coefficient and the stroma for large values of the partition coefficient. The ideal log partition coefficient seems, by all accounts to be in the range of 1-3. Additionally, the normal capacity of a cul-de-sac is 7-10 $\mu$. This can be expanded till $30 \mu \mathrm{l}$ without blinking. Because of this capacity, the conventional drug delivery like eye drops are abolished immediately from the precorneal area and only some amount i.e. 1 to $10 \%$ of the drugs which are topically given gets absorbed. In addition, because of the tear drainage, more than $70 \%$ of the drug which is administered passes through nasolacrimal duct to the GI tract that leads to the systemic side effects $[39,40]$.

\section{Patents}

\section{List of patented ocular product}

Table 1 shows the list of patented ocular products with brand name, active pharmaceutical ingredient and manufacturer name.

\section{List of patents based on ophthalmic drug delivery is tabulated}

Table 2 shows the list of patents based on ophthalmic drug delivery with inventors name, year and work done. 
Table 1: List of patented ocular products.

\begin{tabular}{|c|c|c|c|}
\hline S.No. & Brand name & Active Pharmaceutical Ingredient & Manufacturer name \\
\hline 1 & Alzet & Antibodies, hormones and peptides & Alza Corporation, USA \\
\hline 2 & Iluvien & Flucinolone acetonide & Psivida Inc, USA \\
\hline 3 & Retisert & Flucinolone acetonide & Bausch and laumb Inc. USA \\
\hline 4 & Lacrisert & Cellulose derivatives & Merck and Co. Inc. \\
\hline 5 & Ocusert & Pilocarpine & Alza Corporation, USA \\
\hline 6 & Infusaid & Infusaid & Infusaid Corporation, USA \\
\hline 7 & Ciprodex & Ciprofloxacin, Dexamethasone & Alcon Inc. USA \\
\hline 8 & Elestat & Epinastine HCL & Allergan Inc, USA \\
\hline 9 & Alaway & Ketotifen fumarate & Bausch and laumb Inc. USA \\
\hline 10 & Alrex & Loteprednol etabonate & Bausch and laumb Inc. USA \\
\hline 11 & Muro 128 & Sodium chloride & Bausch and laumb Inc. USA \\
\hline 12 & Zymar & Gatifloxacin & Allergan Inc, USA \\
\hline 13 & Vigamox & Moxifloxacin HCL & Alcon Inc. USA \\
\hline 14 & Lumigan & Bimatoprost & Allergan Inc, USA \\
\hline 15 & Restasis & Cyclosporine & Allergan Inc, USA \\
\hline 16 & Zirgan & Ganciclovir & Bausch and laumb Inc. USA \\
\hline 17 & Azarga & Brinzolamide and timolol & Alcon Inc. USA \\
\hline 18 & Alrex & Loteprednol etabonate & Bausch and laumb Inc. USA \\
\hline 19 & Travatan Z & Travoprost & Alcon Inc. USA \\
\hline 20 & Botox & Botulinum toxin A & Allergan Inc, USA \\
\hline
\end{tabular}

Table 2: Patents based on ophthalmic drug delivery.

S. No Inventors Name and Year

Cetina-Cizmek et al. (2013)

$2 \quad$ Nguyen and Lai (2017)
Work done

References

The invention relates to a process for preparing ophthalmic formulations and to formulations containing a suspension of an ophthalmic drug in an aqueous vehicle. The invention further relates to the production of stable ophthalmic formulations that have a minimal propensity to form drug aggregates.

Ophthalmic formulations containing tyrosine kinase inhibitors, such as Nintedanib, Axitinib, Sorafenib, and Pazopanib are described. The ophthalmic formulations can contain microparticles or nanoparticles of the tyrosine kinase inhibitor. Also described are methods of using the ophthalmic formulations for treating ocular surface diseases, such pterygium, including recurrent pterygium, and hyperemia associated with pterygium.

The present invention are compositions or formulations suitable for application to a patient's eyes which utilizes a topical ophthalmically-acceptable formulation comprising
Abelson and Mcmullin (2013) almically-active anti-inflammatory or steroidal agent in combination with physiologic levels of serum electrolytes in an ophthalmic formulation for the treatment of changes in the normal eye condition.

The present invention relates to an ophthalmic formulation which comprises a fine particle of Compound $\mathrm{A}$ in an aqueous suspension and a manufacturing process

thereof. More specifically, the present invention relates to a topically applied ophthalmic aqueous suspension which is obtainable by suspending fine particles of Compound $\mathrm{A}$ in an aqueous vehicle containing a surfactant and boric acid. The invention also provides processes for making the ophthalmic formulations and to methods of use thereof.

The present invention relates to an ophthalmic formulation which comprises a fine particle of Compound $\mathrm{A}$ in an aqueous suspension and a manufacturing process

thereof. More specifically, the present invention relates to a topically applied ophthalmic aqueous suspension which is obtainable by suspending fine particles of Compound $\mathrm{A}$ in an aqueous vehicle containing a surfactant and boric acid. The invention also provides processes for making the ophthalmic formulations and to methods of use thereof. 
The present invention relates to an ophthalmic formulation which comprises a fine particle of Compound $\mathrm{A}$ in an aqueous suspension and a manufacturing process

thereof. More specifically, the present invention relates to a topically applied

$6 \quad$ William and Takruri (2014)

ophthalmic aqueous suspension which is obtainable by suspending fine particles of Compound $\mathrm{A}$ in an aqueous vehicle containing a surfactant and boric acid. The invention also provides processes for making the ophthalmic formulations and to methods of use thereof.

The present invention are compositions or formulations suitable for application to a patient's eyes which utilizes a topical ophthalmically-acceptable formulation comprising 7 Abelson and Mcmullin a therapeutically-effective amount of an ophthalmically-active antimicrobial agent, and (2014) an ophthalmically-active anti-inflammatory or steroidal agent in combination with physiologic levels of serum electrolytes in an ophthalmic formulation for the treatment of changes in the normal eye condition.

Ophthalmic formulations are provided. The ophthalmic formulations include one or

$8 \quad$ Gerald (2014) more active agents that act to optimize pupil light reflex while minimizing, or effectively eliminating, any undesired eye redness in response to application thereof. The active agents include, for example, alpha 1 antagonists, such as alpha 1a selective antagonists.

Ophthalmic formulations including mycophenolic acid or salt thereof in an aqueous

$9 \quad$ Hou et al. (2017) medium having a reduced level of dissolved oxygen and processes for making such formulations and using such formulations are disclosed.

The present invention provides topical ophthalmic formulations comprising a combination of one or more antihistamine agents and optionally one or more $10 \quad$ Abelson and Matthew vasculature modifying agents such as a ? adrenergic receptor antagonist. Also provided are methods of using the formulations of the invention for treating and/or preventing symptoms associated with migraine headache, and for reducing the frequency, severity and duration of migraine attacks. (2017)

The invention provides ophthalmic formulations containing well-defined substituted

$11 \quad$ Anuradha et al. (2015) gamma lactams. The formulations described herein are useful in treating a variety of ocular diseases related to ocular hypertension, such as for example, glaucoma.

12 Mehmet and Cengiz (2017)

The present application is directed to stable preservative free ophthalmic formulations of opioid antagonists and use thereof in the treatment of retinal degenerative diseases.

The present invention relates to viscosity stabilized ophthalmic formulations and ophthalmic formulations suitable for drug delivery. The formulations comprise 13 Howard et al. (2013) galactomannans such as guar or hydroxypropyl guar and boric acid. The formulations further comprise a diol alcohol such as sorbitol and, optionally, a pharmaceutically acceptable divalent cation salt such as magnesium chloride.

The present invention relates to a process for manufacturing an ophthalmic formulation of a carbonic anhydrase inhibitor, hydroxyl ethyl cellulose (HEC), and a beta-adrenergic antagonist for use in the treatment of ocular hypertension and glaucoma wherein the ophthalmic pharmaceutical formulation is devoid of benzalkonium chloride or any other preservatives. The present process for manufacturing is simpler, cost effective process to prepare the pharmaceutical ophthalmic formulation in a single tank, without the use of additional tanks that can be sterile filtered.

The present disclosure provides novel ophthalmic formulations for ocular 15 Suman and Bronwyn (2013) administration comprising a pharmaceutically effective amount of a combretastatin, from $60 \%$ to $95 \% \mathrm{w} / \mathrm{w}$ pre-gelatinized starch, from $1 \%$ to $10 \% \mathrm{w} / \mathrm{w}$ hydrophilic matrix forming polymer, and from $0.2 \%$ to $5 \%$ lubricant.

An ophthalmic formulation comprising a compound of formula (I): wherein R1 is a

16 Thomas and Burkhardt (2014) linear or branched C9-C33 alkyl or a linear or branched C9-C33 alkenyl with 1 to 4 double bonds; R2 is a linear or branched C9-C19 alkyl or a linear or branched C9-C19 alkenyl with 1 to 4 double bonds; and an ophthalmologically acceptable carrier.

The present invention provides topical ophthalmic formulations comprising a combination of one or more antihistamine agents and optionally one or more vasculature modifying agents such as a ? adrenergic receptor antagonist. Also provided are methods of using the formulations of the invention for treating and/or preventing symptoms associated with migraine headache, and for reducing the frequency, severity

$17 \quad$ Matthew and Richard
(2014)

\author{
and duration of migraine attacks.
}




\begin{tabular}{|c|c|c|c|}
\hline 18 & $\begin{array}{l}\text { Kouyoumjian and Boyd } \\
\qquad(2013)\end{array}$ & $\begin{array}{c}\text { The present invention relates to a process for manufacturing an ophthalmic } \\
\text { formulation of a carbonic anhydrase inhibitor, hydroxyl ethyl cellulose (HEC), } \\
\text { and a beta-adrenergic antagonist for use in the treatment of ocular hypertension } \\
\text { and glaucoma wherein the ophthalmic pharmaceutical formulation is devoid } \\
\text { of benzalkonium chloride or any other preservatives. The present process for } \\
\text { manufacturing is simpler, cost effective process to prepare the pharmaceutical } \\
\text { ophthalmic formulation in a single tank, without the use of additional tanks that can } \\
\text { be sterile filtered. }\end{array}$ & [57] \\
\hline 19 & $\begin{array}{l}\text { Garen and Malcolm } \\
\text { (2013) }\end{array}$ & $\begin{array}{l}\text { An ophthalmic drug delivery device containing a primary medicament reservoir and a } \\
\text { replaceable medicated module containing a second medicament where the device has a } \\
\text { selector to allow dispense of primary medicament or a combination of the primary and } \\
\text { secondary medicaments such that a single activation of the ophthalmic drug delivery } \\
\text { will deliver both medicaments to the user. }\end{array}$ & [58] \\
\hline 20 & Sheue-Fang et al. (2018) & $\begin{array}{l}\text { The invention relates to an ophthalmic drug delivery system that majorly contains } \\
\text { phospholipid and cholesterol for prolonging drug lifetime in the eyes. }\end{array}$ & [58] \\
\hline 21 & William (2001) & $\begin{array}{l}\text { It is an ocular insert that can be disposed by flushing and is composed of polymers like } \\
\text { polyurethanes, polyesters, cellulose acetate, polysaccharides, etc. }\end{array}$ & [59] \\
\hline 22 & Ishikawa et al. (2002) & $\begin{array}{l}\text { It is an electronic component consisting of a drug storage medium which serves as a } \\
\text { reservoir for storing the drug. }\end{array}$ & [60] \\
\hline 23 & Unger (2002) & $\begin{array}{l}\text { This device comprises a gaseous precursor filled microsphere composed of oil, a } \\
\text { surfactant and a therapeutic compound. }\end{array}$ & [61] \\
\hline 24 & $\begin{array}{l}\text { Darougar and Darougar } \\
\qquad(2001)\end{array}$ & $\begin{array}{l}\text { The device is designed to be placed in the upper or lower fornix and had an elongated } \\
\text { polymeric body designed with the flexibility to ease its bending along the curvature of } \\
\text { the eye. }\end{array}$ & [62] \\
\hline 25 & $\begin{array}{l}\text { Chauhan and Gulsen } \\
\text { (2004) }\end{array}$ & $\begin{array}{c}\text { The present invention suggests that the drug diffusion would act as the rate controlling } \\
\text { step. }\end{array}$ & [63] \\
\hline 26 & $\begin{array}{l}\text { Chauhan and Gulsen } \\
\text { (2004) }\end{array}$ & $\begin{array}{l}\text { The present invention depicts that contact lens is composed of drug encapsulated in } \\
\text { nanoparticles uniformly dispersed in the hydrogel matrix forming the transparent lens. }\end{array}$ & [63] \\
\hline 27 & Yaccobi (2002) & $\begin{array}{l}\text { The present invention suggests about implants. It is placed at the outer surface of the } \\
\text { sclera. The device is useful in localized delivery of the drug in the posterior segment of } \\
\text { the eye. }\end{array}$ & [64] \\
\hline 28 & Yaccobi (2004) & $\begin{array}{l}\text { He invented implants using NSAIDs. It has two ends and an injection port to engage } \\
\text { the needle to provide a fluid and a sleeve for forming a ring shaped three dimensional } \\
\text { geometry, and is implanted on the outer surface of the sclera. }\end{array}$ & [65] \\
\hline 29 & Yaccobi (2004) & $\begin{array}{l}\text { The present inventor invented implant. The body of the device was made up of } \\
\text { biocompatible and non-bioerodible material. }\end{array}$ & [65] \\
\hline 30 & $\begin{array}{l}\text { Synder and Dobrucin } \\
\text { (2003) }\end{array}$ & $\begin{array}{l}\text { Implants is a multiple layered device, one of which degrades, or erodes by becoming } \\
\text { available over time to release. }\end{array}$ & [66] \\
\hline
\end{tabular}

\section{CONCLUSION}

It is concluded from the study that there is a unique carrier system offered by ocular drug delivery for many of the pharmaceuticals. Additionally, it has been studied that there are major barriers in pharmacokinetics and ocular drug delivery has to conquer these obstacles. Conquering the barriers must be helpful in the development of a drug delivery system. Nowadays, ocular drug delivery based formulations have been considered as more excellent and acceptable systems for drug delivery because it is more focused on using water soluble and biodegradable polymers. From the extensive literature survey, it has been found that ocular formulations show better results for the localized treatment of eye disease which has minimal side effects as compared to any other routes for drug delivery.

\section{FUTURE PERSPECTIVE}

Even though ophthalmic drug delivery faces so many challenges but still there are enormous ways of future prospects. Therefore, a vast dedication is required for its growth and exposure as well. The main motive of the ophthalmic drug delivery system is to enhance ocular drug absorption despite diminishing systemic absorption. Various perspective showed that experimentally ocular drug absorption can be improved and the continuous increment in the understanding in the process which furnish new future possibilities.

\section{ACKNOWLEDGMENT}

Authors are highly thankful to the Department of Pharmacy, School of Medical and Allied Sciences, Galgotias University, Greater Noida for providing library facilities.

\section{REFERENCES}

1. Sultana Y, Jain R, Rathod R, Ali A, Aqil M. Advances in ophthalmic drug delivery systems: Part I. Latest Rev. 2005;3:2.

2. Kumar GJ, Sudharshan H, Chanukya RD, Mitra AK. Recent Patents and advances in ophthalmic drug delivery. Recent Pat Drug Deliv Formul. 2007;1:161-70.

3. Lang JC, Rodeheaver DP, Missel PJ, Jani R, Chowhan MA, Roehrs R, et al. Design and evaluation of ophthalmic pharmaceutical products. In Banker GS Rhodes CT Eds. Modern Pharmaceutics Marcel Dekker. 2002;415-478.

4. Conway BR. Recent patents on ocular drug delivery systems. Recent Pat Drug Deliv Formul 2008;2:1-8. 
5. Novack GD. Ophthalmic drug delivery: development and regulatory considerations. Clin Pharmacol Ther. 2009;85:539-43.

6. González-Chomón C, Concheiro A, Alvarez-Lorenzo C. Soft contact lenses for controlled ocular delivery: 50 years in the making. Ther Deliv. 2013;4:1141-61.

7. Rivers HM, Chaudhuri SR, Shah JC, Mittal S. A new vision for the eye: unmet ocular drug delivery needs. Pharm Res. 2015;28:14-23.

8. Agrahari V, Mandal A, Agrahari V, Trinh HM, Joseph M, Ray A, et al. A comprehensive insight on ocular pharmacokinetics. Drug Deliv Transl Res. 2016;6:735-754.

9. Patel A, Cholkar K, Agrahari V, Mitra AK. Ocular drug delivery systems: An overview. World J Pharmacol. 2013;2:47-64.

10. Toit LC, Pillay V, Choonara YE, Govender T, Carmichael T. Ocular drug delivery-a look towards nanobioadhesives. Expert Opin Drug Deliv. 2011;8:71-94.

11. Djebli N, Khier S, Griguer F, Coutant AL, Tavernier A, Fabre G, Leriche C, et al. Ocular Drug Distribution After Topical Administration: Population Pharmacokinetic Model in Rabbits. Eur J Drug Metab Pharmacokinet. 2016;42:59-68.

12. Siegal PAN. Glaucoma Medical Therapy: Principles and Management.2008.

13. Dua HS, Faraj LA, Said DG, Gray T, Lowe J. Human corneal anatomy redefined: a novel pre-Descemet's layer (Dua's layer). Ophthalmology. 2013;120:1778-85.

14. Almeida H, Amaral MH, Lobao P, Lobo JM. In-situ gelling systems: a strategy to improve the bioavailability of ophthalmic pharmaceutical formulations. Drug Discov Today. 2014;19:400-412.

15. Gaudana R, Ananthula HK, Parenky A, Mitra AK. Ocular drug delivery. AAPS J. 2010;12:348-360.

16. Makwana SB, Patel VA, Parmar SJ. Development and characterization of in-situ gel for ophthalmic formulation containing ciprofloxacin hydrochloride. Results Pharma Sci. 2016;6:1-6.

17. Mundada AS, Shrikhande BK. Formulation and evaluation of ciprofloxacin hydrochloride soluble ocular drug insert. Curr Eye Res. 2008;33:469-475

18. Marques MR, Loebenberg R, Almukainzi M. Simulated biological fluids with possible application in dissolution testing. Dissolution Technol. 2011;18:15-28.

19. Pandit JK, Bharathi D, Srinatha A, Ridhurkar DN, Singh S. Long acting ophthalmic formulation of indomethacin: evaluation of alginate gel systems. Indian J Pharm Sci. 2007;69:37-40.

20. Van Haeringen NJ. Clinical Biochemistry of Tears. Surv Ophthalmol. 1981;26:84-96.

21. Hillery AM, Lloyd AW, Swarbrick J. Drug Delivery and Targeting for Pharmacists and Pharmaceutical Scientists. Taylor \& Francis New York. 2001.

22. Anumolu SS, Singh Y, Gao D, Stein S, Sinko PJ. Design and evaluation of novel fast forming pilocarpine-loaded ocular hydrogels for sustained pharmacological response. J Controlled Release. 2009; 137:152-59

23. Lin HR, Yu SP, Lin YJ, Wang TS. High pH tolerance of a chitosanPAA nanosuspension for ophthalmic delivery of pilocarpine. J Biomat Sci Polym. 2010;21:141-57.

24. Hagigit T, Nassar T, Behar-Cohen F, Lambert G, Benita S. The influence of cationic lipid type on in-vitro release kinetic profiles of antisense oligonucleotide from cationic nanoemulsions. Eur J Pharm Biopharm. 2008;70:248-259.

25. Patel V and Agrawal YK. Current status and advanced approaches in ocular drug delivery system. J global trends pharma sci. 2011;2:131-148.

26. Degim T, Celebi N. Controlled delivery of peptides and proteins. Curr Pharm Des. 2007;13:99-117.

27. Shivhare R, Pathak A, Shrivastava N, Singh C, Tiwari G, Goyal R. An update review on novel advanced ocular drug delivery system. World J Pharma and Pharma Sci. 2012;1:545-568.

28. Seo KY, Han SJ, Cha HR, Seo SU, Song JH, Chung SH, et al. Eye mucosa: an efficient vaccine delivery route for inducing protective immunity. J Immunol. 2010;185:3610-3619.

29. Kumar P, Rajeshwarrao P. Nonionic surfactant vesicular systems for effective drug delivery-an overview. Acta Pharmaceutica Sinica B. 2011;1:208-219.

30. Raizman MB, Hamrah P, Holland EJ, Kim T, Mah FS, Rapuano CJ, et al. Drug-induced corneal epithelial changes. Surv Ophthalmol. 2017;62:286-301.

31. Toropainen E, Ranta VP, Talvitie A, Suhonen P, Urtti A. Culture model of human corneal epithelium for prediction of ocular drug absorption. Invest Ophthalmol Vis Sci. 2001;42:2942-2948.

32. Reichl S, Bednarz J, Müller-Goymann CC. Human corneal equivalent as cell culture model for in vitro drug permeation studies. Br J Ophthalmol. 2004;88:560-565.

33. Reichl S. Cell culture models of the human cornea- a comparative evaluation of their usefulness to determine ocular drug absorption in vitro. J Pharm Pharmacol. 2008;60:299-307.

34. Mannermaa E, Vellonen KS, Ryhanen T, Kokkonen K, Ranta VP, Kaarniranta $\mathrm{K}$, et al. Efflux protein expression in human retinal pigment epithelium cell lines. Pharm Res. 2009;26:1785-1791.

35. Barar J, Asadi M, Mortazavi-Tabatabaei SA, Omidi Y. Ocular drug delivery; Impact of in vitro cell culture models. J Ophthalmic Vis Res. 2009;4:238-252.

36. Laddha UD, Mahajan HS. An insight to ocular in-situ gelling systems. Int J Adv Pharm. 2017;6:31-40.

37. Malhotra M, Majumdar DK. Permeation through cornea. Ind J Exp Biology. 2011;39:11-24.

38. Amaliyar PR, Chaudhary S. In-situ gel forming a novel approach for sustained ophthalmic drug delivery. Int J Pharm Sci Bio Sci. 2014;3:502-524.

39. Bhalerao AV, Singh SS. In situ gelling ophthalmic drug delivery system for glaucoma. Int J of Pharm and Bio Sci. 2011;2:7-14.

40. Kuno N, Fujii S. Recent advance in ocular drug delivery systems. Polymers. 2011;3:193-221.

41. Cetina-Cizmek B, Bracko D, Miocic S, Tunjic I. Ophthalmic formulations and processes for their preparation. 2013.

42. Nguyen T, Lai CY. Ophthalmic formulations of tyrosine kinase inhibitors, methods of use and preparation methods. 2017.

43. Abelson M, Mcmullin K. Ophthalmic formulations and uses thereof. 2013.

44. Mcvicar WK, Takruri H. Ophthalmic formulations. 2017.

45. Mcvicar WK, Takruri H. Ophthalmic formulations. 2014.

46. Abelson M, Mcmullin K. Ophthalmic formulations and uses thereof. 2014.

47. Horn G. Ophthalmic formulations including selective alpha 1 antagonist. 2014.

48. Hou SYE, Bowman LM, Nguyen T, Peyman G. Ophthalmic formulations of mycophenolic acid. 2017. 
49. Abelson MB, Chapin MJ. Topical Ophthalamic formulations for the treatment and prevention of Migraine Headache. 2017.

50. Gore AV, Jordan RS, Parashar A, Pujara C, Graham R. Ophthalmic formulations containing substituted gamma lactams and methods for use thereof. 2015.

51. Pisak MN, Celayir C. Stable preservative free ophthalmic formulations of opoid antagonists. 2017.

52. Ketelson HA, Davis JW, Meadows DL. Stabilized ophthalmic galactomannan formulations. 2013.

53. Shah MV, Bahri D, Singh MK. Presevative Free Ophthalmic Pharmaceutical formulation. 2016.

54. Sharma S, Siim BG. Ophthalmic formulations. 2013.

55. Millar T, Schuett B. Ophthalmic formulation. 2014.

56. Chapin MJ, Abelson R. Topical opthalamic formulations for the treatment and prevention of Migraine headache. 2014.
57. Kouyoumjian G, Boyd MS. Ophthalmic Drug delivery device with a Medicated module. 2013.

58. Shih SF, Chang PC, Tseng YL, Guo LSS, Hong K. Ophthalmic Drug Delivery System containing phospholipid and cholesterol. 2018.

59. Williams SF. Flushable disposable polymeric products. 2001.

60. Ishikawa A, Takeda N, Ahn SI, Ahn SS, Hayes SR, Gaffney FA, et al. Implantable drug delivery systems. 2002.

61. Unger EC. Acoustically active drug delivery systems. 2002.

62. Darougar S, Darougar D. Ocular insert. 2001.

63. Chauhan A, Gulsen D. Ophthalmic drug delivery device. 2004.

64. https://patents.google.com/patent/US6416777

65. Yaacobi Y. Ophthalmic drug delivery device. 2004.

66. Snyder ME, Dobrusin EM. Sustained release ophthalmological device and method of making and using the same. 2003. 